\title{
Réplica - A Sociologia é um Esporte de Combate - uma Réplica ao Texto de Sueli e Cristina
}

\section{Sociology is a Combat Sport - a Response to Sueli and Cristina's Text}

Paulo Prochno* Ph.D. em Administração de Empresas pelo INSEAD, Fontainebleau, França. Professor na Robert H. Smith School of Business, University of Maryland, Estados Unidos.

*Endereço: Robert H. Smith School of Business - University of Maryland, Van Munching Hall, College Park, MD 20742.E-mail: pprochno@rhsmith.umd.edu 
O título se refere a um documentário (La sociologie est en sport de combat, dirigido por Pierre Carles, 2001), que cobre o período entre 1998 e 2001 das atividades profissionais de Pierre Bourdieu. Concorde-se ou não com as idéias dele, a imagem que fica é de um intelectual sempre pronto para o combate, para levar suas idéias aos mais diferentes públicos e construir conhecimento a partir do diálogo, do contraste. Bourdieu sabia que defender uma idéia significava levar essa idéia também para quem não concorda com ela, e a partir daí tentar mudar o mundo.

Esta réplica procura apresentar uma visão diferente sobre um dos temas abordados por Sueli e Cristina - internacionalização da produção acadêmica brasileira. Meu argumento principal aqui é: disseminar conhecimento passa por internacionalizar nossa produção, criando diálogos com o que é feito em outros países, mesmo que numa posição de antagonismo, porque ficar num canto, cercado somente das pessoas que pensam de forma parecida, é deixar de cumprir a função mais importante de um acadêmico.

E daí fica o dilema: como levar a idéia para esse público mais amplo? Com a proliferação de publicações pelo mundo, com os novos meios de distribuir informação, fica difícil acompanhar tudo o que se passa na sua área de conhecimento. A maneira mais fácil de levar sua idéia para o público mais amplo possível - e com isso estabelecer diálogos com vários grupos que estudam o mesmo assunto em outros lugares - é publicar nos periódicos considerados A pela comunidade internacional. Esses são os periódicos mais lidos e, em muitas universidades, são os únicos periódicos lidos. Não publicar neles significa simplesmente não ser lido por muitos acadêmicos de excelência que poderiam contribuir muito para que as idéias do autor encontrem maior profundidade e ressonância. A comunidade acadêmica internacional existe como grande rede de ajuda para melhorar o conhecimento gerado. Claro que nesse processo certas contribuições são preferidas em relações a outras de qualidade similar, mas a comunidade é diversa e há muitas possibilidades para que um acadêmico que pesquise uma questão relevante encontre um veículo para disseminar suas idéias. De forma geral, a chamada comunidade dominante internacional (aquela afiliada às escolas consideradas de qualidade excepcional) está bastante aberta a estudos com metodologias e enfoques diferentes, e especialmente interessada no conhecimento gerado em outros contextos, para que os modelos atuais sejam refinados e reflitam melhor as diversas realidades pelo mundo.

Acusar a comunidade acadêmica de desenvolver um pensamento único é deixar de lado grandes tradições de pensamento em nossa área. O caráter eminentemente contingencial da administração é reconhecido há décadas, assim como a influência das diferentes instituições sobre a atividade econômica. Ao contrário de áreas 
como a economia, estamos longe de ter uma visão dominante nas principais escolas. O campo é plural, tanto nos temas que aborda quanto nas metodologias e disciplinas de base. Há muito diálogo, muita discordância, mas também bastante respeito mútuo. Vejamos um exemplo já antigo: em 1995, houve um debate no Organization Science entre John Van Maanen e Jeffrey Pfeffer - o primeiro do MIT, o segundo de Stanford. Pfeffer defendeu, num artigo de 1993 no Academy of Management Review (Pfeffer, 1993) a adoção de um paradigma único em organizações para que o conhecimento gerado avançasse de forma mais rápida. Maanen (1995) atacou essa idéia (e a suposta "cientificidade" que Pfeffer almejava), defendendo que teorias dependem de contexto e, portanto, o campo precisa de muito mais diversidade, diferentes contextos, visões não-ortodoxas. Esses argumentos foram publicados há mais de 10 anos num periódico considerado A pela comunidade internacional, encontrando ressonância num público mais amplo. Van Maanen pode ser minoria entre as escolas mais importantes, mas uma coisa em que ele sempre insistiu (ele foi um de meus orientadores no doutorado) foi levar idéias dissonantes para o debate nos veículos de maior ressonância e com isso construir a dialética de que o campo precisa. Nunca haverá dialética, se houver tribos separadas, cada uma com sua visão, sem se comunicarem.

E para o diálogo acontecer de forma eficiente, precisa-se de uma língua em comum. O uso do inglês é forma de facilitar isso, já que o esperanto não deu certo e o francês diminuiu sua influência. É claro que ler Bourdieu em francês, Berger e Luckmann em alemão ou Selznick em inglês é muito melhor que ler traduções, e digo isso por experiência própria; mas, dada a realidade atual quanto ao domínio de línguas estrangeiras pela população em geral, ter uma língua como padrão facilita o diálogo. E o padrão atual é o inglês, como já foi o francês e como pode ser o chinês dentro de algum tempo. O ponto positivo é que com o uso do inglês, o conhecimento que geramos no Brasil pode gerar valor para acadêmicos em países como Índia, Tailândia, China, África do Sul... Os problemas em vários países podem ser similares aos nossos; portanto estabelecer diálogo com a comunidade internacional, como um todo, é essencial para clarificar essas possíveis ligações e ter mais massa crítica para estudar certos temas. A lógica por trás é que quanto maior o número de pessoas pensando sobre os mesmos problemas, maior a chance de gerar soluções relevantes; para isso precisa-se de língua e métodos em comum. Com isso, o inglês acaba por democratizar o acesso à informação, diminuindo a necessidade de custosas traduções entre línguas pouco faladas. Com isso, os benefícios alcançados são muito maiores que o preço, ao contrário do argumentado por Sueli e Cristina. Mesmo porque dominar línguas estrangeiras é bastante benéfico: amplia horizontes, perspectivas, melhora a capacidade de expressão. Se alguém paga um preço, são os acadêmicos dos EUA e outros países de língua inglesa: ao não aprenderem uma nova língua, deixam de ter os benefícios que viriam nesse aprendizado. Sorte 
a nossa que o português não é a língua comum para a comunicação entre diferentes nacionalidades.

Essa visão de construir diálogos não quer dizer que não existam grupos diferentes com interesses diferentes, e parte do trabalho do acadêmico é achar sua tribo, porque nosso conhecimento é geralmente bem especializado. Mas há amplo espaço dentro das publicações de elite para um diálogo entre as tribos, basta achar os periódicos que desenvolvem temas próximos a seus interesses. O debate acima citado entre o Pfeffer e o Maanen é um exemplo disso. Ou o recente debate no Journal of International Business Studies entre Hofstede e acadêmicos do projeto Globe sobre como medir culturas (Hofstede, 2006). É claro que as publicações tendem a refletir o que seus editores pensam; então acaba havendo certa predileção por determinados temas ou metodologias - e isso não reflete uma estratégia deliberada de dominação, sendo apenas o reflexo dos temas vistos por certos acadêmicos de reconhecida competência, como os mais relevantes naquele momento; e isso varia de periódico para periódico. Por exemplo, apesar de ter uma colega de departamento que é editora do Academy of Management Journal, sei que é muito difícil meu trabalho ser publicado lá, por diferentes razões. Mas isso não significa que eu não admire o trabalho dela, e ela o meu, e que ambos possamos contribuir para melhorar o trabalho um do outro. E que meu trabalho não possa ser publicado em outros periódicos, também excelentes, que tenham foco diferente.

\section{A Questão do Acesso}

Existe certamente o problema de as publicações mais expressivas na área serem usualmente de domínio privado; mas há opções diversas de acesso via base de dados (Ebsco, Proquest), diminuindo o possível custo por artigo. Ainda assim, isso está longe de ser a solução. Esse é um problema que ainda temos de enfrentar, mas ferramentas como o Google Scholar e o fato de vários autores e escolas colocarem seus trabalhos em suas páginas na web estão contribuindo para democratizar o acesso ao conhecimento. Hoje em dia é muito fácil achar working papers na internet. Dado o longo período necessário para se publicar um artigo, o acesso mais relevante para desenvolver conhecimento de ponta é o acesso a working papers, ou seja, o conhecimento que está sendo produzido agora (e não o que foi produzido há 3 ou 4 anos e foi publicado agora). Além disso, todos os autores com quem entrei em contato até hoje, pedindo um determinado artigo, atenderam meu pedido, ou seja, se você usar o Google Scholar e achar algo que interessa, basta entrar em contato com o autor. E não, essas ferramentas não são toscas, como descrito pelas autoras. São um passo adiante em relação aos antigos sistemas de catálogo em biblioteca, facilitando nosso trabalho, 
tanto para achar as idéias dominantes como para garimpar novas idéias. Os sistemas de busca da maioria das grandes bibliotecas pelo mundo é de acesso livre quem quiser achar referências usando as bibliotecas, ao invés de ferramentas como Google Scholar ou base de dados, tem essa opção.

Há iniciativas institucionais também: o MIT coloca grande parte do seu conteúdo didático online, disponível ao público em geral (http://ocw.mit.edu), Cornell (http:// eclips.cornell.edu/) e Stanford (http://edcorner.stanford.edu/) disponibilizam material multimedia para uso pessoal ou em sala de aula. Há também iniciativas individuais de professores que publicam seus livros com licença Creative Commons (como Eric von Hippel, do MIT), facilitando bastante o acesso ao conhecimento.

E aí entramos em outra questão importante: levar o conhecimento ao público não acadêmico. Já fazemos isso por meio de nossos cursos, palestras, artigos em jornais; esses instrumentos de disseminação local do conhecimento são importantíssimos. Os periódicos internacionais cumprem um papel diferente, muito mais de ajudar na geração do que na disseminação do conhecimento. Com eles se constroem diálogos que ajudam o conhecimento, para que geremos informações mais profundas, mais bem articuladas e com maior impacto potencial. Sendo a administração de empresas uma ciência de caráter eminentemente aplicado, nossa obrigação é, a partir daí, disseminar esse conhecimento ao público que precisa dele, caso em que definitivamente não são os acadêmicos, mas o público que pratica a administração. E nesse âmbito, precisamos desenvolver meios democráticos para a divulgação desse conhecimento (como, por exemplo, as iniciativas do MIT citadas acima).

\section{Internacionalizar - Mas Onde Publicar?}

Por último, trago aqui uma contribuição a um diálogo que tem acontecido no Brasil nos últimos anos: onde publicar seu trabalho? Claro que o que vem a seguir depende de duas premissas: você concorda com pelo menos parte dos meus argumentos acima, e quer aumentar a chance de ter seu trabalho lido por seus pares pelo mundo. Nesse caso, acho que não há necessidade de se tentar reinventar a roda: há muita informação disponível na internet sobre isso. William Starbuck, professor da NYU, há tempos disponibiliza em sua página estudos de citações e rankings de importância de periódicos (http://pages.stern.nyu.edu/ wstarbuc/). Anne-Wil Harzing, atualmente na Austrália, tem em sua página uma lista que resume vários estudos já feitos, bem como softwares gratuitos que ajudam na análise de citações (http://www.harzing.com/resources.htm\#/jql.htm). Essa página traz muitos artigos interessantes para esse debate, como uma comparação entre os 
índices do Google Scholar e do ISI, mostrando a superioridade do índice do Google (Harzing \& Wal, 2008), ou uma análise detalhada do impacto de publicações, com base em várias classificações existentes (Harzing \& Mingers, 2007).

De forma geral, pelo menos na minha área específica (estratégia / organizações), há um consenso quanto aos periódicos mais importantes: Academy of Management Journal, Academy of Management Review, Administrative Science Quarterly, Management Science, Organization Science, Strategic Management Journal; diferentes escolas incluirão alguns mais nessa lista dependendo de suas ênfases (como o Research Policy ou o Journal of International Business Studies). Esses são os periódicos que serão efetivamente lidos na maioria das escolas - se você quiser estabelecer diálogos mais amplos, ao invés de conversar só com seus vizinhos, deve procurar publicar nesses periódicos, porque quanto mais amplo o alcance de suas idéias, maior o poder que você terá de efetivamente mostrar como as teorias precisam ser ou não adaptadas a diferentes contextos.

O esporte é de combate. E isso pressupõe ir ao encontro daqueles com quem você concorda e, mais importante, daqueles com quem discorda. Desse contraste nasce o novo conhecimento. Temos sorte de fazer parte de um período na história onde as novas tecnologias aproximam as pessoas, mostrando o muito que há de comum entre elas. Com isso elas poderão também entender melhor as diferenças.

\section{ReferênCIAs Bibliográficas}

Harzing, A. W., \&

Mingers, J. (2007).

Ranking journals in business and management: a statistical analysis of the harzing dataset. European Journal of Information Systems, 16(4), 303-316.

Harzing, A. W., \&

Wal, R. van der (2008).

A Google Scholar h-index for journals: a better metric to measure journal impact in economics \& business? [Submetido]. Academy of Management Annual Meeting, Anaheim, California.
Hofstede, G. (2006).

What did GLOBE really measure? Researchers' minds versus respondents' minds. Journal of International Business Studies, 37(6), 882-896.

Maanen, J. van (1995).

Style as theory. Organization Science, 6(1), 133-143.

Pfeffer, J. (1993).

Barriers to the advance of organizational science: paradigm development as a dependent variable. Academy of Management Review, 18(4), 599-620. 